\title{
Galvanostatic Interruption of Lithium Insertion into Magnetite: Evidence of Surface Layer Formation
}

\author{
Nicholas W. Brady ${ }^{1}$, K. W. Knehr ${ }^{1}$, Christina A. Cama ${ }^{2}$, Christianna N. Lininger ${ }^{1}$, Zhou Lin ${ }^{2}$, \\ Amy C. Marschilok ${ }^{2,4}$, Kenneth J. Takeuchi ${ }^{2,4}$, Esther S. Takeuchi ${ }^{2,3,4}$, and Alan C. West ${ }^{1}$ \\ ${ }^{1}$ Department of Chemical Engineering, \\ Columbia University, New York, NY 10027 \\ ${ }^{2}$ Department of Chemistry \\ Stony Brook University, Stony Brook, NY 11794 \\ ${ }^{3}$ Energy Sciences Directorate \\ Brookhaven National Laboratory, Upton, NY 11973 \\ ${ }^{4}$ Department of Materials Science and Engineering \\ Stony Brook University, Stony Brook, NY 11794
}

Submitted: December, 2015

Revised: March, 2016

Email: acw7@columbia.edu

Fax: +1 212-854-3054 


\section{Introduction}

Nanostructuring of lithium-insertion materials may improve the performance of lithiumion batteries by increasing the surface area to volume ratio and by lowering the solid-state diffusion resistances in the electrodes [1-9]. Increasing the surface area to volume ratio is beneficial because it provides more sites for the electrochemical reactions, thereby decreasing surface overpotential for a given nominal current density. However, extensive nanostructuring may have negative effects because it increases the amount of active material that can be exposed to side reactions and surface layer formation [10-12]. For instance, during the first cycle(s) of a lithium-ion battery, reactions between the electrolyte and the electrodes may result in the formation of thin layers of material on the electrode surfaces, commonly referred to as the solid electrolyte interphase (SEI) for graphite anodes and the cathode electrolyte interphase for 
cathodes [13-15]. The formation of these layers typically involves the transformation of active material into a surface layer, thereby reducing theoretical capacity [13].

Herein, we compare simulations to experiments and hypothesize that the complex potential transients upon current interruption seen after a relatively small amount of lithium is inserted into magnetite $\left(x=0.5,1.0\right.$, and 1.5 in $\left.\mathrm{Li}_{x} \mathrm{Fe}_{3} \mathrm{O}_{4}\right)$ is related to the formation of a thin layer of inactive material. In short, for small crystal sizes (6 and $8 \mathrm{~nm}$ ) the potential initially increases due to relaxation of the concentration profile of reduced lithium, and then at longer times, decreases. Previous simulations capture the initial rise in potential caused by rearrangement of solid-state lithium $[16,17]$, but the fall in potential during relaxation cannot be explained. We hypothesize that it is caused by transformation of the active material $\left(\mathrm{Fe}_{3} \mathrm{O}_{4}\right)$ into inactive material. The transformation is confined to the crystal surface and occurs through a (as of yet unidentified) reaction, which increases the concentration of intercalated lithium in the remaining active material. The coupling of these effects - concentration profile relaxation by mass transport (rise) and increase of intercalated lithium (fall) - gives better experimental agreement. This paper uses the previously described mass-transfer model and incorporates a mechanism for surface layer formation. The formation of the surface layer appears to occur via nucleation and growth, which is qualitatively consistent with literature [18]. The Avrami model describes the formation of the surface layer [19-21].

\section{Experimental}

Experiments were conducted using electrodes comprised of nanocrystalline magnetite. Small crystals, 6 and $8 \mathrm{~nm}$ average diameter, were synthesized using a co-precipitation method previously reported by the authors $[8,22]$. Larger crystals, $\sim 32 \mathrm{~nm}$ (data not shown), were 
purchased from Alpha Aesar. Electrodes were prepared using 90\% magnetite, 5\% carbon, and 5\% polyvinylidene fluoride binder (by weight) coated onto an aluminum foil substrate. Each electrochemical test was performed using a two-electrode coin-type experimental cell with a lithium metal anode and $1 \mathrm{M} \mathrm{LiPF}_{6}$ in 1:1 dimethyl carbonate: ethylene carbonate as the electrolyte. The electrodes had a nominal thickness of $50 \mu \mathrm{m}$ and a nominal active mass loading of $4.1 \mathrm{mg} \mathrm{cm}^{-2}$.

Galvanostatic interruption experiments were conducted for electrodes comprised of nanocrystalline magnetite with average diameters of 6,8 and $32 \mathrm{~nm}$. The experimental cells were first lithiated at a $\mathrm{C} / 200$ rate $\left(4.63 \mathrm{~mA} \mathrm{~g}^{-1}\right.$ of $\left.\mathrm{Fe}_{3} \mathrm{O}_{4}\right)$ to $x=0.5,1.0,1.5$, and 2.0 electron equivalents per $\mathrm{Fe}_{3} \mathrm{O}_{4}$ and then held at open circuit for up to 30 days. After the rest period, the cells were delithiated to a cutoff voltage of $3.0 \mathrm{~V}$ using a C/200 rate, followed by a constant voltage oxidation at $3.0 \mathrm{~V}$ for two hours. Subsequently, a second experiment was performed, where the current interruption was applied after the reduction of a specified amount of charge, which was equivalent to the amount of charge passed during the first lithiation.

In addition, second lithiation experiments were conducted at a rate of $\mathrm{C} / 100\left(9.26 \mathrm{~mA} \mathrm{~g}^{-1}\right.$ of $\mathrm{Fe}_{3} \mathrm{O}_{4}$ ) for electrodes made of $42.5 \% \mathrm{Fe}_{3} \mathrm{O}_{4}, 42.5 \%$ acetylene carbon black, and $15 \%$ polyvinylidene fluoride binder (PVDF) by weight. The magnetite was lithiated at the $\mathrm{C} / 100$ rate until a charge of $100 \mathrm{mAh} \mathrm{g}^{-1}$ was passed. The magnetite was subsequently delithiated to a cutoff voltage of $3.0 \mathrm{~V}$ at the same $\mathrm{C} / 100$ rate and then held at $3.0 \mathrm{~V}$ for 1 hour, and lithiated again at $\mathrm{C} / 100$ to the same capacity, $100 \mathrm{mAh} \mathrm{g}^{-1}$ [23]. All voltage recovery experiments were conducted at $30^{\circ} \mathrm{C}$ using a freshly fabricated cell. 


\section{Theory}

This section provides an outline of the present model, which was developed by modifying a previously validated multi-scale model to include the effects of the transformation of active material $[16,17]$. Table 1 contains a comparison of the governing equations for the two models. Consistent with multi-scale simulation results for 6 and $8 \mathrm{~nm}$ crystals, the present model assumes mass transport resistances only occur on the agglomerate length scale (i.e., no concentration variations within the crystals or across the bulk electrode). This assumption provides a valid approximation for the present experiments, where the focus is on understanding the complex voltage transients during the relaxation of electrodes comprised of crystals with diameters of 6 and $8 \mathrm{~nm}$. The transport of lithium-ions in the agglomerate is simulated using dilute solution theory. The concentration of lithium-ions in the agglomerate is coupled to the concentration of solid-state lithium in the crystals through a Butler-Volmer kinetic expression. It is assumed that the formation of the surface layer has a negligible impact on the reaction kinetics. The thermodynamic potential as a function of lithium in the solid-state and in the agglomerate $U\left(c_{x}, c_{a g g}\right)$ - was modeled by fitting a modified Nernst equation to experimental data.

The rate of change of solid-state lithium within the crystals, $c_{x}$, is calculated from the following material balance:

$$
\frac{\partial\left(\varepsilon_{\text {active }} c_{x}\right)}{\partial t}=-\frac{a i_{r x n}}{F}
$$

When held at the open circuit, the local current density $i_{r x n}$ may not be zero because the crystals within the agglomerate galvanically interact until the concentration variations completely relax. $\varepsilon_{\text {active }}$ is the volume fraction of active material in the electrode. It is given by 


$$
\text { active }=(1 \quad) \frac{V_{x, 0} V_{S}}{V_{x, 0}}, \quad V_{x, 0}=\frac{4}{3} r_{x}^{3}
$$

where $\xi$ is the volume fraction of magnetite in the surface layer. For these simulations, $=50 \%$ and it is assumed that $=0.26$, consistent with closed packed spheroidal crystals. Other volume fractions $\xi$ were explored, and they did not have a significant impact on the simulated results. Equations 1 and 2 were formulated assuming the transformation of magnetite to an inactive phase does not alter the total amount of solid-state lithium within the remaining magnetite. This implies that the local concentration of solid-state lithium within the active material increases as a result of the loss of active magnetite.

\section{w/o $\mathrm{Fe}_{3} \mathrm{O}_{4}$ Transformation (agglomerate-only)}

$\mathrm{w} / \mathrm{Fe}_{3} \mathrm{O}_{4}$ Transformation (agglomerate-only)

Mass

(agg.)

$$
\varepsilon \frac{\partial c_{a g g}}{\partial t}=\varepsilon D_{a g g} \frac{\partial^{2} c_{a g g}}{\partial r^{2}}+\frac{2 \varepsilon D_{a g g}}{r} \frac{\partial c_{a g g}}{\partial r}+\frac{a i_{r x n}}{F}
$$

(crystal)

$$
\begin{gathered}
c_{x}=\frac{a i_{r x n}}{F} \\
- \\
i_{r x n}=i_{0}\left[\exp \left(\frac{\alpha_{a} F\left(\varphi_{1}-U\right)}{R_{G} T}\right)-\exp \left(\frac{-\alpha_{c} F\left(\varphi_{1}-U\right)}{R_{G} T}\right)\right] \\
i_{0}=F k_{r x n} c_{a g g}^{\alpha_{a}} c_{x}^{\alpha_{c}}\left(c_{x, \max }-c_{x}\right)^{\alpha_{a}}
\end{gathered}
$$

No change

$$
\begin{gathered}
\frac{\left(\text { active }_{x}\right)}{t}=\frac{a i_{r x n}}{F} \\
\text { active }=(1) \frac{V_{x, 0} V_{S}}{V_{x, 0}}
\end{gathered}
$$

No change

No change

Table 1. Comparison of governing equations for model with and without transformation of $\mathrm{Fe}_{3} \mathrm{O}_{4}$ to an inactive state due to reactions with the electrolyte. 


\subsection{Surface Layer Formation}

The surface layer formation was initially modeled assuming a uniform, layer-by-layer growth. The results were able to capture some of the salient features of the OCP relaxation. However, better agreement was achieved by assuming a nucleation-and-growth mechanism, whereby the volume of the surface layer can be described through the Avrami model [19-21]:

$$
V_{S}=V_{\text {max }, S}\left[1 \quad \exp \left(k_{S} t^{n}\right)\right]
$$

When the exponent $n=1$, equation 3 is consistent with a layer-by-layer growth mechanism. More generally, $n$ is determined by the relative rate of nucleation to growth and the dimensionality of the growth (e.g., two- $v s$. three-dimensional). The value of $V_{\max , S}$ is set by a final thickness of the surface layer:

$$
V_{\max , S}=\frac{4}{3}\left(r_{x}^{3} \quad\left(r_{x} \quad \max ^{3}\right)\right.
$$

where $\lambda_{\max }$ is the maximum thickness of the surface layer, which was determined from the final measured open circuit potential.

Along with increasing the size of the crystals, the formation of the inactive layer is expected to increase the overall size of the agglomerate. In the present study, the agglomerate radius may, at most, increase by a factor of $7 / 6$, which corresponds to a $1 \mathrm{~nm}$ thick surface layer forming on the $6 \mathrm{~nm}$ crystals (see below for further discussion on the model fitting of ${ }_{\max }=1$ $\mathrm{nm})$. Simulations incorporating a 7/6 expansion of the agglomerate were conducted, but they did not have a significant impact on the simulated results. Therefore, the present model does not include the expansion of the agglomerate. 


\subsection{Salt Saturation Limit}

During delithiation, the concentration of lithium salt within the pores of the agglomerate increases due to the slow mass transport processes. If the concentration exceeds the solubility limit of the salt, an additional solid-phase precipitates, and this plugs the pores and prevents the electrochemical reactions from occurring. To account for this process, the model includes the following conditional statement on the reaction current:

$$
i_{r x n}=\left\{\begin{array}{cc}
i_{r x n} & c_{a g g}<c_{s a t} \\
0 & c_{a g g} \geq c_{s a t}
\end{array}\right.
$$

In equation 5, $c_{a g g}$ is the concentration of lithium salt in the agglomerate pores, and $c_{\text {sat }}$ is the saturation concentration where the salt starts to precipitate. To the best of the authors' knowledge, the exact value of $c_{\text {sat }}$ for this system has not been published. Therefore, $c_{\text {sat }}$ was taken as a fitted parameter in the model. It was selected to ensure that the simulated delithiation reached the $3.0 \mathrm{~V}$ cutoff at the same time as the experiments.

Equations 2-4 along with the equations outlined in Table 1 were solved using a numerical algorithm outlined by Newman [24]. Physical properties were assumed to be the same as given in references 13, 14. In all cases, simulations were performed to be as consistent as possible with the experimental protocols. When the saturation limit was included in the model, the simulated and experimental charge passed prior to the cutoff voltage was in excellent agreement. To ensure a reasonable comparison between theory and experiment when the salt saturation limit was not included, the cells were oxidized at a rate of $\mathrm{C} / 200$ until an equivalent number of coulombs were passed. The simulations were then held at open-circuit for the remainder of the experimental oxidation time (see Figure 3). Continuous operation simulations followed the experimental protocol in ref. 19. 


\section{Results and Discussion}

Figure 1 shows the experimental and simulated voltage during recovery after a lithiation at $\mathrm{C} / 200\left(4.63 \mathrm{~mA} \mathrm{~g}^{-1}\right.$ ) until an average lithium concentration of $x=0.5$ (for $x$ in $\mathrm{Li}_{\mathrm{x}} \mathrm{Fe}_{3} \mathrm{O}_{4}$ ). The experimental voltage curve rises to a maximum after approximately 100 hours and appears to plateau. After 200 hours, the potential falls until it begins to reach a steady state at around 400 hours. The initial rise in voltage is explained by relaxation of concentration profiles within the agglomerate, and the subsequent decline in voltage is due to inactive layer formation. Qualitatively similar results are seen for 8-nm crystals, but no maximum is observed for the variation of the open circuit potential for 32-nm crystals. 


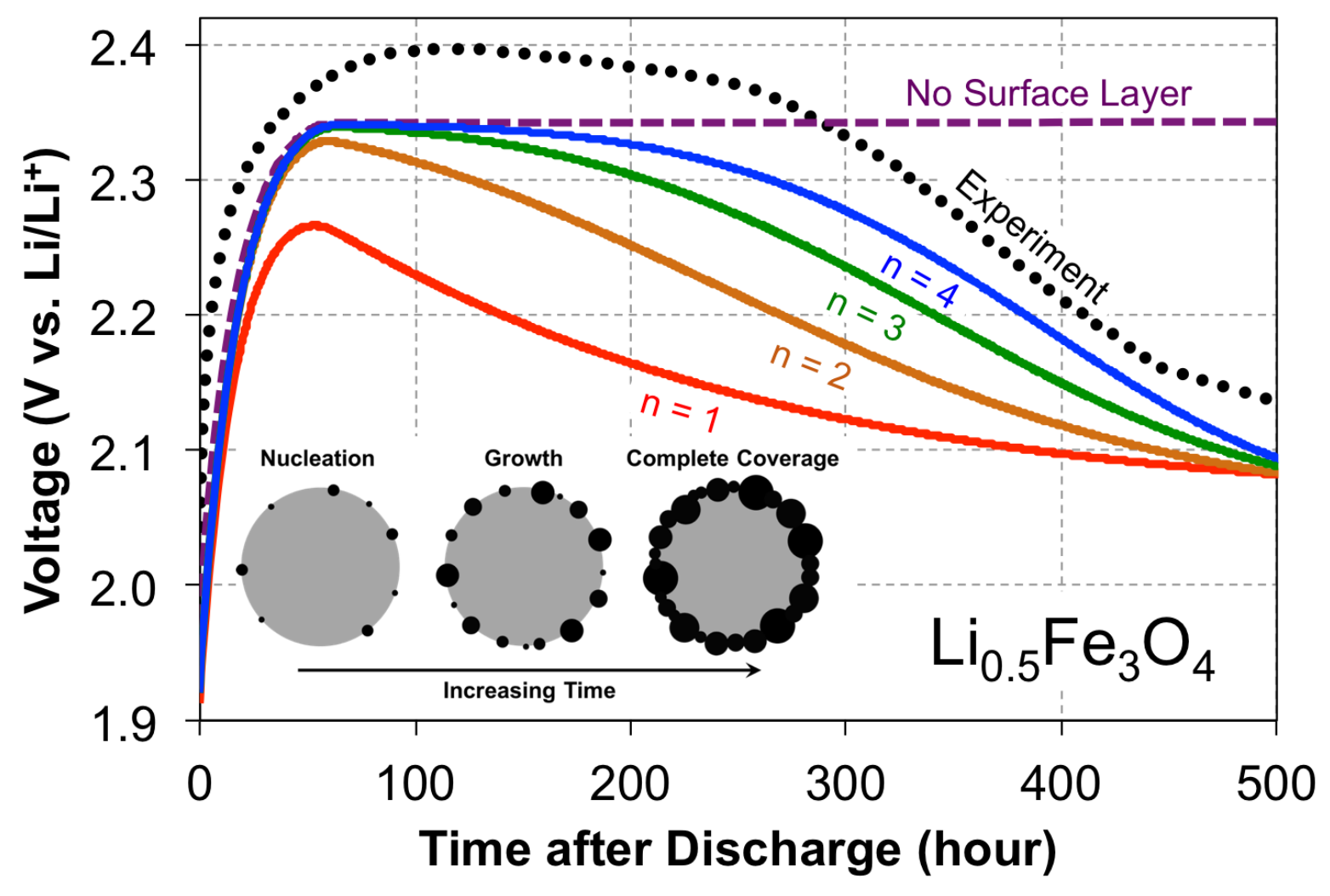

Figure 1. Voltage recovery for $6 \mathrm{~nm} \mathrm{Fe}_{3} \mathrm{O}_{4}$ electrodes that were initially lithiated to an average lithium concentration of $\mathrm{Li}_{0.5} \mathrm{Fe}_{3} \mathrm{O}_{4}$. Simulations with surface layer formation were conducted using $n=1,2,3$, or 4 in the Avrami equation (Eq. 3). Inset provides a visualization of the proposed mechanism of surface layer formation: progressive nucleation and three-dimensional growth $(n=4)$.

The simulations in Figure 1 are based on the original model (no surface layer formation) as well as the modified model with surface layer formation. For each of the models with surface layer formation, the parameter $k_{S}$ was adjusted to obtain the best fit. The agreement between experiment and simulation when $n=3$, or $n=4$ is particularly compelling. The physical interpretation implies that the phase grows through a nucleation and growth process. However, it cannot be concluded definitively whether the nucleation is progressive or instantaneous or if the 
growth is two-dimensional or three-dimensional. It is assumed that surface layer growth terminates when magnetite is no longer in direct contact with electrolyte. The two parameters used to fit the model to experiment were $k_{S}$ and $\lambda_{\max }$, with $k_{s}=2.0 \times 10^{-25} s^{-4}$ when $n=4$, and ${ }_{\max }=1 \mathrm{~nm}$. The reported surface layer thickness is within the range reported in the literature for surface layers $[10,13,25,26]$.
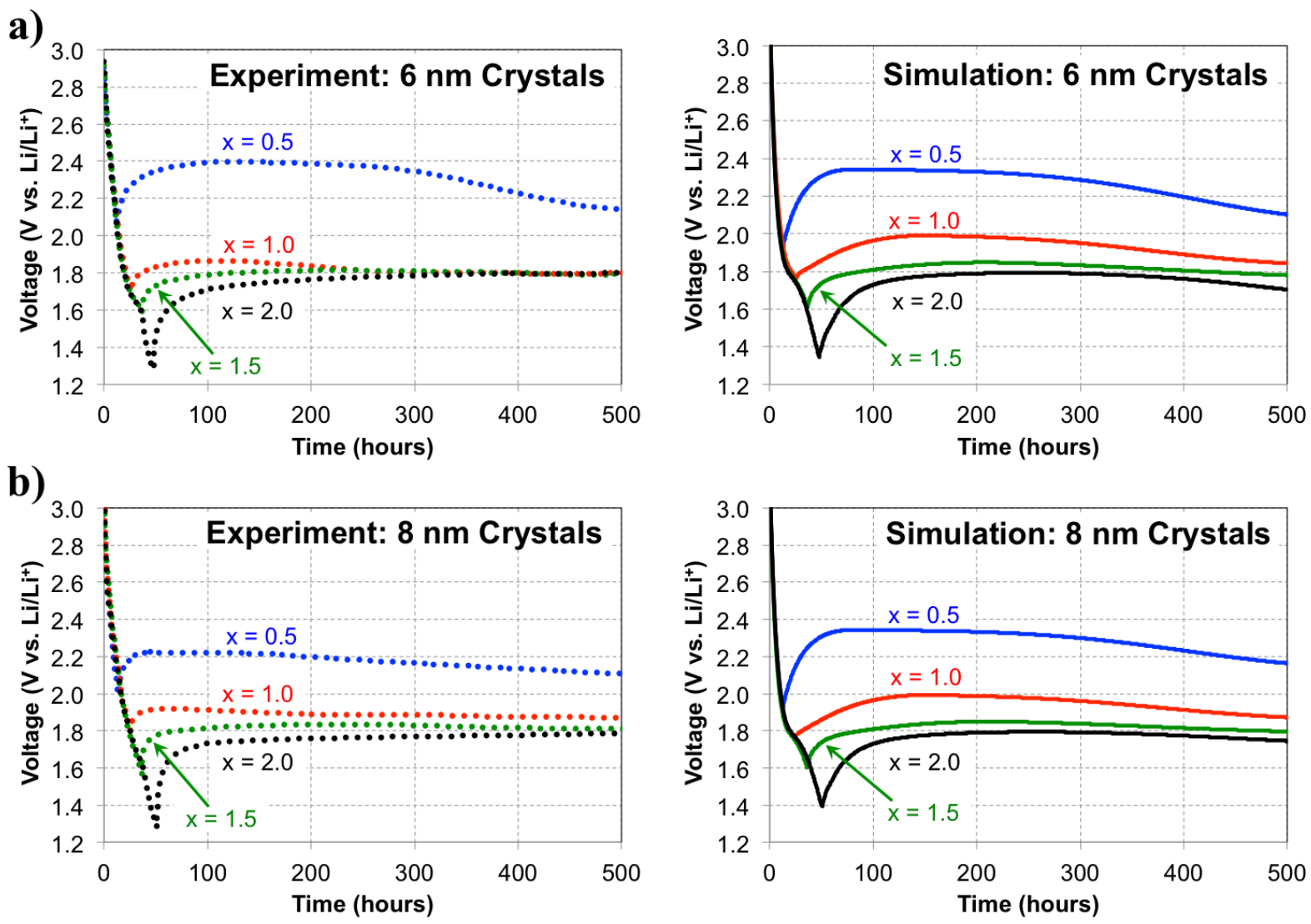

Figure 2. Side by side comparisons of experimental and simulated lithiation and voltage recovery for electrodes comprised of a) $6 \mathrm{~nm}$ and b) $8 \mathrm{~nm}$ crystals. Recovery was conducted after lithiation to different levels of intercalation (i.e., $x$ in $\mathrm{Li}_{\mathrm{x}} \mathrm{Fe}_{3} \mathrm{O}_{4}$ ). Each experiment was conducted with a separate cell.

Figure 2 shows a comparison of simulated $(\mathrm{n}=4)$ and measured transients for interruption after reduction to different levels of lithiation for 6 and $8 \mathrm{~nm}$ crystals. The initial 
drop in potential corresponds to insertion of lithium, and the initial rise indicates the beginning of recovery after current interruption. Comparisons are made without adjustment of the values of $k_{S}$ and $\lambda_{\max }$. In general, good agreement is observed between the simulations and experiments. Discrepancies may be attributed to changes in the nucleation and growth kinetics at different depths of lithiation. For instance, inactive layer formation can be influenced by many factors including the cell potential and the lithiation time [27-29]. While a detailed analysis of the relationship between the kinetic parameters $\left(k_{S}\right.$ and $\left.\lambda_{\max }\right)$ and the operating conditions may be beneficial, it is currently out of scope with this work.

At higher degrees of lithiation (e.g., $x=1.5$ and 2.0), both experimental and simulated results in Fig. 2 show no or very small maxima in the open circuit potential. The simulations suggest that the disappearance in the maximum is not because the surface layer is already fully formed. Instead, the maxima disappear because the open circuit potential does not change significantly in the range $1.0 \quad x \quad 2.0$ (for $x$ in $\mathrm{Li}_{\mathrm{x}} \mathrm{Fe}_{3} \mathrm{O}_{4}$ ). This can be observed in Figure 5 of Ref. 13, which shows the fit of the open circuit voltage equation to experimental voltage recovery data. When simulations are extended to 32-nm crystals, the simulations correctly predict only small maxima with potential (data not shown). This result is consistent with an assumption that the volume fraction transformed is proportional to the crystal surface area and that the surface layer thickness is the same for all crystal sizes. For instance, assuming that ${ }_{\max }$ does not vary with crystal size, only a small percentage of the active material is transformed in the 32-nm crystals, which minimizes the increase in the solid-state lithium concentration. For example, the simulations indicate that a fully formed surface layer on a 32-nm crystal would only increase the concentration of solid-state lithium from $x=0.5$ to $x \sim 0.55$, which corresponds to a $33 \mathrm{mV}$ change in voltage. This is a small variation when compared to the case with 6-nm 
crystals, where the concentration of solid-state lithium is predicted to increase by over $70 \%$ (from $x=0.5$ to $x \sim 0.86,270 \mathrm{mV}$ ).

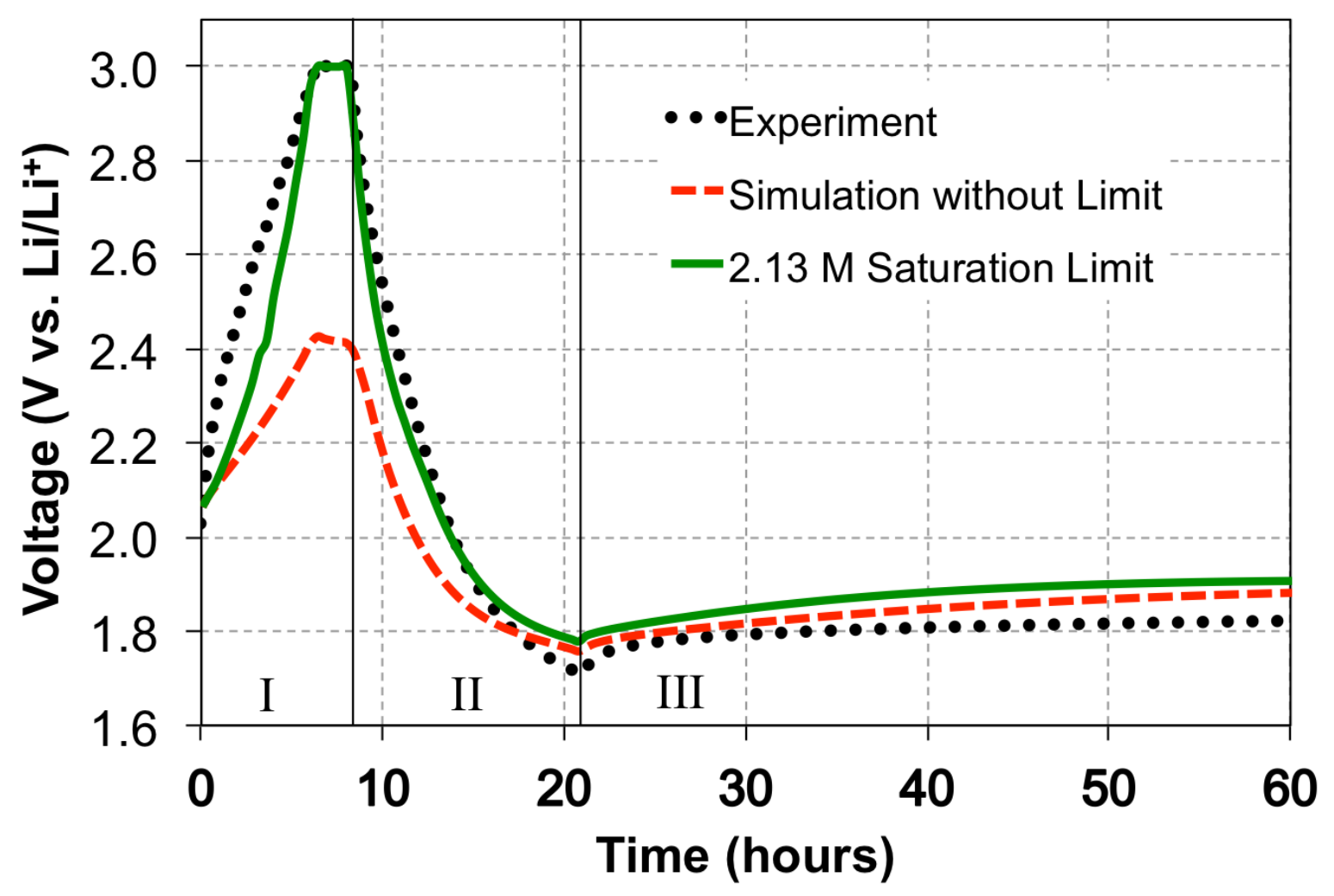

Figure 3. Experimental and simulated voltage during: I) first oxidation at $C / 200$, then constant voltage hold at $3.0 \mathrm{~V}$ ), II) second reduction at C/200, and III) second voltage recovery (open circuit). The first oxidation was conducted after a reduction to $x=0.5$ (for $x$ in $\mathrm{Li}_{x} \mathrm{Fe}_{3} \mathrm{O}_{4}$ ) and an OCP relaxation for 30 days.

Another test of the hypothesis is to compare potential-time variation for the first and second reduction cycles. Figure 3 shows the experimental and simulated voltage curves for a cell that rested at open circuit for 30 days at a state of $x=0.5$ in $\mathrm{Li}_{x} \mathrm{Fe}_{3} \mathrm{O}_{4}$. Initially, the electrode was driven anodically to a cutoff voltage of $3.0 \mathrm{~V}$. Next, the cell was held at $3.0 \mathrm{~V}$ for 2 hours. Coulometric analysis of the experimental data in Figure 3 show that $x \sim 0.25$ at the end of 
oxidation. The cell was then lithiated to $x \sim 0.75(0.25+0.50)$, and allowed to relax. Simulations with and without a salt saturation limit show that including a solid-salt phase precipitation dramatically improves agreement with the experimental potential. Solid-salt precipitation is a factor because during the first voltage recovery solid-state lithium relaxes to a uniform concentration throughout the agglomerate. When the agglomerate is delithiated, poor mass transport through the agglomerate causes the concentration of oxidized lithium-ions in the pores to build up at the center of the agglomerate, eventually surpassing the saturation concentration.

Based on this analysis, delithiation of magnetite should be easier if the solid-state lithium does not redistribute toward the center of the agglomerate. This suggests that oxidation is less difficult if the electrode is operated continuously. For example, for magnetite reduced to an average concentration of $x=1.0$ (results not shown), simulations predict that $\Delta x=-0.76$ (prior to a $3.0 \mathrm{~V}$ cutoff) can be achieved by delithiation at a constant rate of $\mathrm{C} / 100$ (experimental value is $\Delta x=-0.78)$ if the oxidation current is applied immediately after the reduction reaction. However, if the electrode rests at OCP for 30-days prior to the oxidation reaction, simulations predict $\Delta x=$ -0.5 , in accord with the experimental value of $\Delta x=-0.55$ electron equivalents.

Further evidence that the surface layer reduces capacity can be seen from an analysis of the first and second lithiation processes of the galvanostatic interruption experiments, c.f. Figures 2 and 3. For instance, experiments show a reduction in specific energy between the first and second lithiation processes of $14 \%, 11 \%$, and $11 \%$ for cells lithiated to $\Delta \mathrm{x}=0.5,1.0$, and 1.5 respectively, whereby $\Delta \mathrm{x}$ corresponds to the change of lithiation. The specific energy was determined by integrating the power vs. time curves. Simulations of these experimental studies that account for surface-layer formation are in accord with experiments (predicted reduction of 
specific energies of $11 \%, 9 \%$, and $16 \%$, respectively). Simulations without the surface layer formation predicted specific-energy reductions of $3 \%, 1 \%$, and $2 \%$, with the reductions arising from an incomplete delithiation during the charging protocol. While the present simulations incorporating surface-layer formation are in fair agreement with experiments, a more complex model may be able to capture the impact of potential-time history on the surface layer, possibly leading to improvements in the predictions.

a)

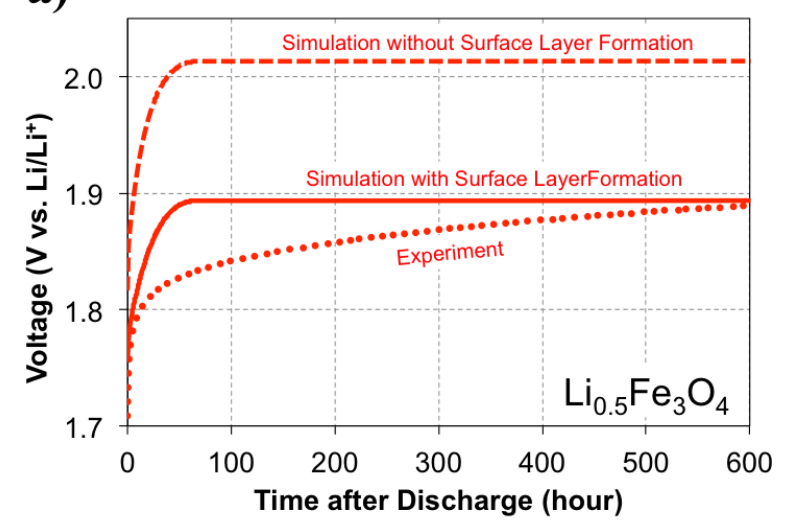

b)

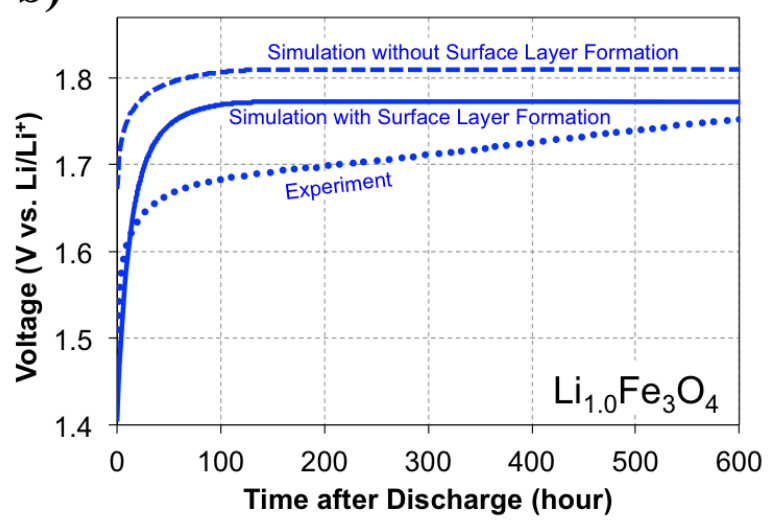

Figure 4. Experiments and simulations of the second voltage recovery with simulations accounting for (solid) and not accounting for (dashed) active material transformation. Comparisons are made for a) $x=0.5$ and b) $x=1.0$ in $\mathrm{Li}_{\mathrm{x}} \mathrm{Fe}_{3} \mathrm{O}_{4}$.

Figure 4 shows the experimental and simulated voltage recovery ( $c f$. , zone III of figure 3 ), for $x=0.5$ and for $x=1.0$. When the impact of inactive layer formation is included, the simulations of the potential recovery after the second lithiation step are in much better agreement with the final OCP. However, the simulations predict a more rapid transition to the steady-state OCP than is seen experimentally. It appears as if the diffusion coefficient is lower after the formation of the surface layer on the magnetite. One explanation is that the surface mobility of 
lithium on the new surface is significantly decreased, as this is believed to impact the agglomerate-scale diffusion coefficient.

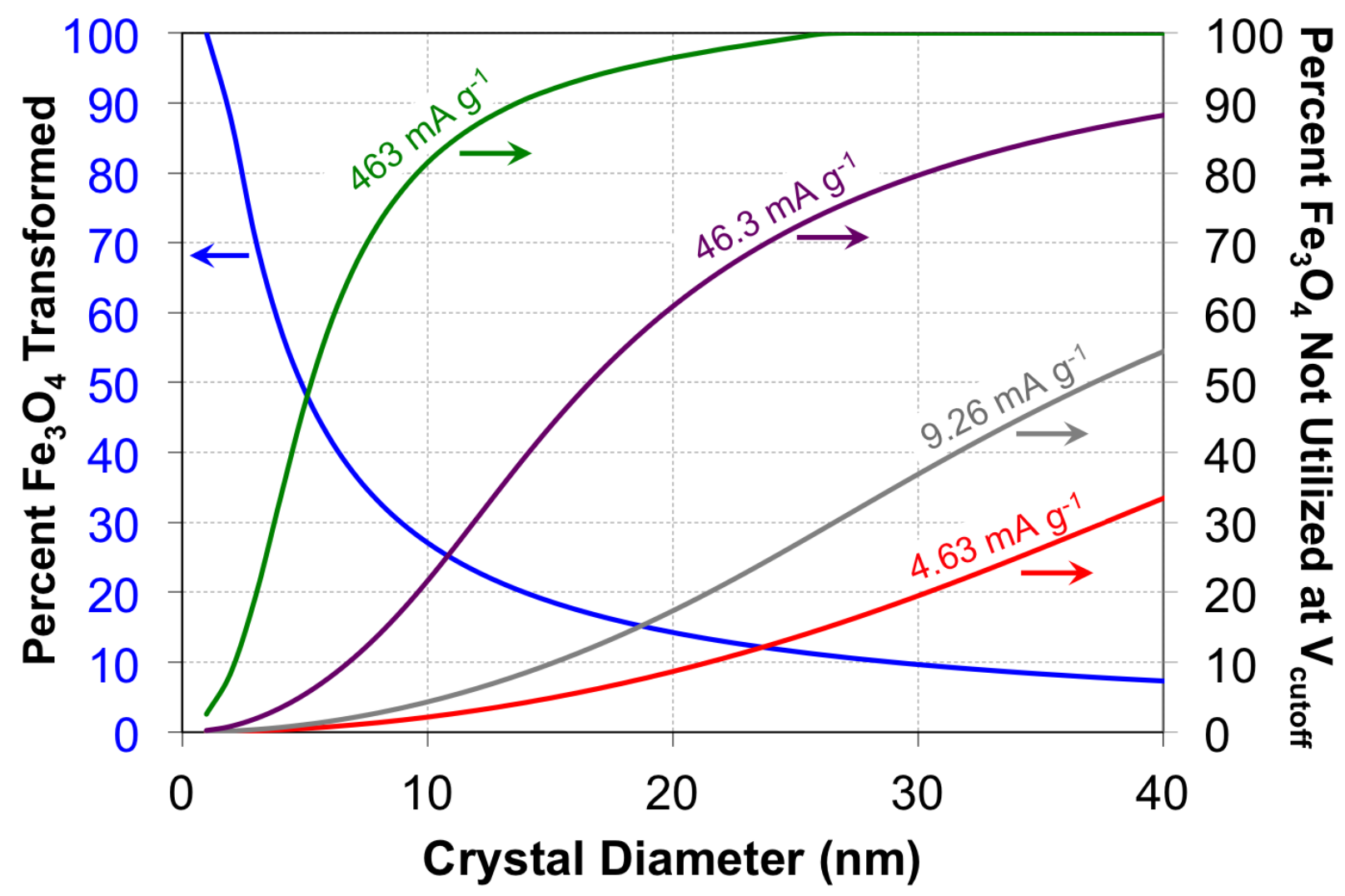

Figure 5. Plot comparing the active material lost (not utilized) due to transformation (left-axis) and active material not utilized due to solid-state transport resistances (right-axis).

Figure 5 summarizes the impact of nanosizing magnetite on electrode capacity. Assuming that a $0.5 \mathrm{~nm}$ layer of magnetite is transformed into a surface layer, the fraction of active material lost decreases rapidly with increasing crystal size. However, depending on lithiation rates and transport resistances, large crystal sizes result in a significant fraction of the magnetite not being used prior to the lithiation cutoff potential. To illustrate this effect, we have simulated performance of a hypothetical magnetite electrode with varying crystal sizes and varying insertion rate. The battery is hypothetical because it is assumed that it has been 
fabricated in such a manner that the only transport resistance in the battery is the solid-state diffusion in the crystal. Presently, as constructed, agglomerate scale diffusion is another significant resistance within the magnetite electrodes $[16,17]$. Simulations were conducted using dilute solution theory with $D_{x}=2.0 \times 10^{-18} \mathrm{~cm}^{2} \mathrm{~s}^{-1}$, and a cutoff voltage of $1.5 \mathrm{~V}$.

Results, shown for four lithiation rates, illustrate that the fraction of unused magnetite increases as crystal radius increases. Clearly, the trend is the opposite for the fraction of magnetite transformed by surface layer formation. The results summarized in Figure 5 are hypothetical because they assume agglomerate-free electrode construct and cannot be quantitatively compared to experiments. Depending on the application, an optimal crystal size may exist, where performance may even decline if the crystal is made too small. While the above asserts that inactive layer formation may have a negative effect on capacity for nanoparticles, it is well documented that SEIs (a type of surface layer) have an important role in improving stability, cyclability, rate capability, and safety in lithium ion batteries [13, 14, 30-35].

At present, the precise composition and structure of the surface layer identified in this work are unknown. The surface layer may correspond to the transformation of magnetite to a different, less reversible phase. It may also correspond to the formation of an SEI on the magnetite surface, similar to that observed by Lee et al. for 10 to 12-nm crystals [36]. Either way, the simulated results suggest that a portion of the active material is lost, which reduces the capacity of the material.

\section{Conclusions}

Magnetite reacts with electrolyte to form a surface layer, and when the magnetite is made nanocrystalline, a significant fraction of the active material may be transformed. It is suggested 
by the open-circuit potential relaxation that during surface layer formation, the intercalated lithium is concentrated in the remaining magnetite. Comparisons of simulations to experiments suggest that the surface layer formation can be described by a nucleation and growth mechanism. Agreement with experimental oxidation data can be improved by accounting for a saturationinduced solid-salt formation within the pores of the agglomerate. The process of surface layer formation is very complicated. This particular system allowed for insights into the formation process, but it is unclear if the methods outlined here can be extended to other chemistries.

\section{Acknowledgements}

This work was supported as part of the Center for Mesoscale Transport Properties, an Energy Frontier Research Center supported by the U. S. Department of Energy, Office of Science, Basic Energy Sciences, under award \#DE-SC0012673. The computing was performed on the Yeti Shared HPC Cluster at Columbia University, which includes support from Empire State Development's Division of Science, Technology, and Innovation under contract number C090171. K. W. K. and C. N. L greatly acknowledge the support of the National Science Foundation Graduate Research Fellowship under Grant No. DGE-11-44155. Any opinions, findings, and conclusions or recommendations expressed in this material are those of the authors and do not necessarily reflect the views of the National Science Foundation. 


\section{List of Symbols}

$a \quad$ specific surface area $\left(\mathrm{cm}^{2} \mathrm{~cm}^{-3}\right)$

$c_{a g g} \quad$ lithium concentration in the agglomerate $\left(\mathrm{mol} \mathrm{cm}{ }^{-3}\right)$

$c_{\text {sat }} \quad$ saturation limit of lithium salt in the electrolyte $\left.(\mathrm{mol} \mathrm{cm})^{-3}\right)$

$c_{x} \quad$ solid-state lithium concentration $\left(\mathrm{mol} \mathrm{cm}^{-3}\right)$

$D_{x} \quad$ solid-state diffusion coefficient $\left(\mathrm{cm}^{2} \mathrm{~s}^{-1}\right)$

F $\quad$ Faraday's constant $\left(96,485 \mathrm{C} \mathrm{mol}^{-1}\right)$

$i_{r x n} \quad$ reaction rate $\left(\mathrm{A} \mathrm{cm}^{-2}\right)$

$k_{S} \quad$ reaction rate constant of the surface layer formation $\left(\mathrm{s}^{-4}\right)$

$n \quad$ denotes mode of nucleation and growth

$r_{x} \quad$ crystal radius $(\mathrm{cm})$

$t \quad$ time (s)

$V_{\text {agg }} \quad$ agglomerate volume $\left(\mathrm{cm}^{3}\right)$

$V_{x} \quad$ crystal volume $\left(\mathrm{cm}^{3}\right)$

$V_{S} \quad$ surface layer volume $\left(\mathrm{cm}^{3}\right)$

$V_{\max , S} \quad$ maximum surface layer volume $\left(\mathrm{cm}^{3}\right)$

$\varepsilon_{\text {active }} \quad$ volume fraction of active material

$\lambda_{\max } \quad$ maximum surface layer thickness $(\mathrm{cm})$

$\xi \quad$ volume fraction of magnetite in the surface layer

\section{$\underline{\text { Subscript }}$}




$$
\begin{array}{ll}
\text { agg } & \text { denotes agglomerate } \\
x & \text { denotes crystal } \\
S & \text { denotes surface layer }
\end{array}
$$

\section{References}

[1] S. Mitra, P. Poizot, A. Finke, J.M. Tarascon, Advanced Functional Materials, 16 (2006) $2281-2287$.

[2] S.K. Vikram Sivakumar, Caroline A. Ross, and Yang Shao-Horn, IEEE Transactions on Magnetics, 43 (2007) 3121-3123.

[3] Z.-M. Cui, L.-Y. Jiang, W.-G. Song, Y.-G. Guo, Chemical Materials, (2009) 1162-1166.

[4] S. Komaba, T. Mikumo, A. Ogata, Electrochemistry Communications, 10 (2008) 1276-1279.

[5] S. Komaba, T. Mikumo, N. Yabuuchi, A. Ogata, H. Yoshida, Y. Yamada, Journal of The Electrochemical Society, 157 (2010) A60-A65.

[6] M.C. Menard, A.C. Marschilok, K.J. Takeuchi, E.S. Takeuchi, Electrochimica Acta, 94 (2013) 320-326.

[7] M.C. Menard, A.C. Marschilok, K.J. Takeuchi, E.S. Takeuchi, Physical chemistry chemical physics : PCCP, 15 (2013) 18539-18548.

[8] S.L. Zhu, A.C. Marschilok, E.S. Takeuchi, G.T. Yee, G.B. Wang, K.J. Takeuchi, J. Electrochem. Soc., 157 (2010) A1158-A1163.

[9] S. Zhu, A.C. Marschilok, C.-Y. Lee, E.S. Takeuchi, K.J. Takeuchi, Electrochemical and Solid-State Letters, 13 (2010) A98-A100.

[10] R.A. Ali-zade, Inorganic Materials, 42 (2006) 1215-1221. 
[11] R.W. Chantrell, J. Popplewell, S.W. Charles, IEEE Transactions on Magnetics, 14 (1978) 975-977.

[12] R. Kaiser, G. Miskolczy, Journal of Applied Physics, 41 (1970) 1064-1066.

[13] P. Verma, P. Maire, P. Novak, Electrochimica Acta, 55 (2010) 6332-6341.

[14] P.B. Balbuena, Y. Wang, Lithium-Ion Batteries: Solid-Electrolyte Interphase, Imperial College Press, 2003.

[15] R. Fong, U.v. Sacken, J.R. Dahn, Journal of The Electrochemical Society, 137 (1990) 20092013.

[16] K.W. Knehr, N.W. Brady, C.N. Lininger, C.A. Cama, D.C. Bock, Z. Lin, A.C. Marschilok, K.J. Takeuchi, E.S. Takeuchi, A.C. West, ECS Transactions, 69 (2015) 7-19.

[17] K.W. Knehr, N.W. Brady, C.A. Cama, D.C. Bock, Z. Lin, C.N. Lininger, A.C. Marschilok, K.J. Takeuchi, E.S. Takeuchi, A.C. West, Journal of The Electrochemical Society, 162 (2015) A2817-A2826.

[18] R.N. Methekar, P.W.C. Northrop, K. Chen, R.D. Braatz, V.R. Subramanian, Journal of The Electrochemical Society, 158 (2011) A363.

[19] M. Avrami, The Journal of Chemical Physics, 7 (1939) 1103-1112.

[20] M. Avrami, The Journal of Chemical Physics, 8 (1940) 212-224.

[21] M. Avrami, The Journal of Chemical Physics, 9 (1941) 177-184.

[22] S.L. Zhu, A.C. Marschilok, E.S. Takeuchi, K.J. Takeuchi, Electrochem Solid St, 12 (2009) A91-A94.

[23] D.C. Bock, K.C. Kirshenbaum, J. Wang, W. Zhang, F. Wang, J. Wang, A.C. Marschilok, K.J. Takeuchi, E.S. Takeuchi, ACS Applied Materials \& Interfaces, 7 (2015) 13457-13466. [24] J. Newman, Karen E. Thomas-Alyea, Electrochemical Systems, Wiley Interscience, 2004. 
[25] D. Aurbach, Journal of Power Sources, 89 (2000) 206-218.

[26] T. Yoshida, M. Takahashi, S. Morikawa, C. Ihara, H. Katsukawa, T. Shiratsuchi, J.-i.

Yamaki, Journal of The Electrochemical Society, 153 (2006) A576-A582.

[27] D. Aurbach, M.D. Levi, E. Levi, A. Schechter, Journal of Physical Chemistry B, 101 (1996) 2195-2206.

[28] E. Peled, D. Golodnitsky, C. Menachem, D. Bar-Tow, Journal of The Electrochemical Society, 145 (1998) 3482-3486.

[29] J. Li, E. Murphy, J. Winnick, P.A. Kohl, Journal of Power Sources, 102 (2001) 302-309.

[30] J. Xu, Y. Hu, T. Liu, X. Wu, Nano Energy, 5 (2014) 67-73.

[31] X. Wu, J. Guo, M.J. McDonald, S. Li, B. Xu, Y. Yang, Electrochimica Acta, 163 (2015) 93101.

[32] Z. Zhang, D. Fouchard, J.R. Rea, Journal of Power Sources, 70 (1997) 16-20.

[33] G. Park, H. Nakamura, Y. Lee, M. Yoshio, Journal of Power Sources, 189 (2009) 602-606.

[34] Y. Zheng, Y.-B. He, K. Qian, B. Li, X. Wang, J. Li, S.W. Chiang, C. Miao, F. Kang, J.

Zhang, Electrochimica Acta, 176 (2015) 270-279.

[35] M. Matsui, K. Dokko, Y. Akita, H. Munakata, K. Kanamura, Journal of Power Sources, 210 (2012) 60-66.

[36] S.H. Lee, S.H. Yu, J.E. Lee, A. Jin, D.J. Lee, N. Lee, H. Jo, K. Shin, T.Y. Ahn, Y.W. Kim, H. Choe, Y.E. Sung, T. Hyeon, Nano Lett, 13 (2013) 4249-4256. 